\title{
Physiological and ethological effects of glutathione, a powerful antioxidant food complement; a study on ants as models
}

\begin{abstract}
Glutathione is a natural compound present in every cell, and acting essentially as an antioxidant. It is nowadays produced by humans as a food complement recommended for staying in good health. Its potential adverse effects have not yet been investigated. We thus did so using ants as models. Glutathione did not affect the ants' tactile perception and relationship with young and adult members of their colonies or aliens. It induced no stress, and scarcely ameliorated their learning and memory. Ants developed no adaptation, as well as no habituation to glutathione consumption. However, this food complement decreased the ants' food consumption, and increased their activity, speed of locomotion, audacity, and slightly some cognitive abilities (f.i. their ability in crossing a twists and turns path). The ants became somewhat dependent on glutathione, the effects of which rapidly decreased since $2-2 \frac{1}{2}$ to $7-71 \frac{1}{2}$ hours after weaning, and this decrease was followed by a recovering period during which the ants were less active than usual. Glutathione did not act as a drug such as cocaine, or as an energizing product. It acted rather like a doping substance enhancing some physical and cognitive performances. Humans may discover such an effect and may use glutathione with this aim. They may then become dependent on the product. This should be known by practitioners, pharmacists and anyone whose job consists in evaluating humans' performances.
\end{abstract}

Volume 2 Issue 2 - 2017

\author{
Marie Claire Cammaerts \\ Department of Organizational Biology, Free University of \\ Brussels, Belgium
}

Correspondence: Marie-Claire Cammaerts, Department of Organizational Biology, Free University of Brussels, Independent researcher, 27, Square du Castel Fleuri, I I 70, Brussels, Belgium, Tel 32267349 69, Email mtricot@ulb.ac.be, mccammaerts@gmail.com

Received: October 22, 2017 | Published: November 06, 2017

Keywords: activity, audacity, cognition, dependence, food consumption, memory, social relationship

\begin{abstract}
Abbreviations: ang.deg, angular degrees; ang.deg./cm, angular degrees per $\mathrm{cm} ; \mathrm{mm} / \mathrm{s}$, millimeter per second; $\chi^{2}$, chi square; vs, versus; $\mathrm{n}^{\circ}$, number; $\mathrm{cm}$, centimeter; $\mathrm{mm}$, millimeter; $\mathrm{ml}$, mil liliter; $\mu \mathrm{l}$, micro liter; $\mathrm{mg}$, milligram; $\mathrm{s}$, second: min, minute; $\mathrm{h}$, hours; $\mathrm{t}$, time; $\%$, percentage
\end{abstract}

\section{Introduction}

Glutathione is the tri-peptide yL-glutamyl-L-cysteinylglicine (Figure 1) which exists under an oxidized and a reduced form. It is present in nearly all the cells of a living organism. It allows these cells keeping adequate redoxy potential, and acts in detoxification and eliminatory functions. Under its reduced form, it is the most important cellular antioxidant. In fact, it is essential to the cell survival. ${ }^{1}$ Decreases of its amount occur at the end of the life, and in case of diseases such as arterioscleroses, Alzheimer or Parkinson. Glutathione is used by practitioners for caring of persons suffering from cancer, neurological diseases, cardiac problems, diabetes, hepatices and kidneys problems (https://fr.wikipedia.org/wiki/ glutathion). Most of the internet links relative to glutathione, as well as notices jointed to drugs or food complements containing it bring to the fore its efficiency as an antioxidant: it is the best antioxidant; it has no known adverse effects" [https://www.alternativesante.fr/ glutathion/le-seul-antioxydant-dont-on-ne-nous-parle-j...; www.boncoin-sante.com/...glutathion.../questions-diverses-sur-le-glutathioneclaircis; www.nutranews.org/sujet.pl?id=109; supervitaminec.com/ le-super-antioxydant-glutathion/; https://www.sante-detox.com , ... > Detoxication des métaux lourds; https://selfhacked.com/.../30scientifically-proven-health-benefits-...; https:/www.ncbi.nlm.nih. gov > ... > PubMed Central (PMC)].

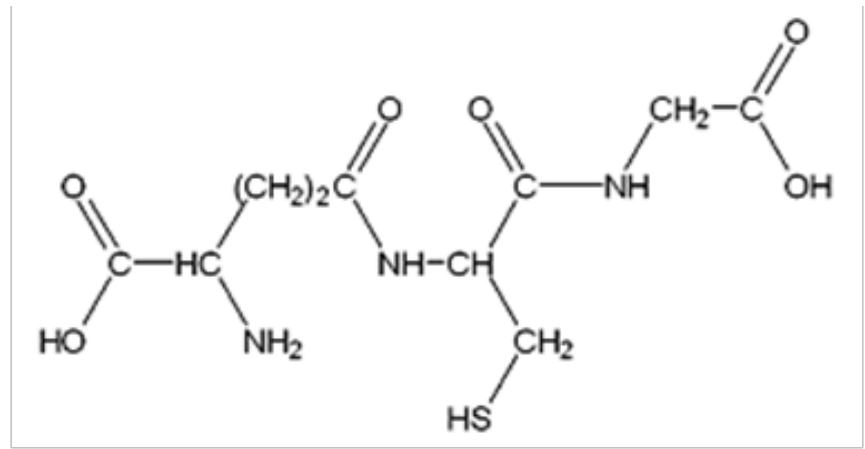

Figure I Chemical structure of glutathione, a natural tripeptide, present in every cell, acting as a strong antioxidant. It is normally devoted to improve health and to make the skin clearer; it is also used for caring of persons suffering from severe diseases such as cancer, diabetes, neurodegenerative diseases, vascular diseases, problems of kidneys, liver and lungs functioning. Food complements containing glutathione can be found in any drugstore under tablets, capsules, patches and injectable products. In these drugs and food complements, the glutathione is present under an acetyl form (the radical acetyl being located on the $\mathrm{S}$ function of glutathione) in order to stay intact until it reaches the cells of the organism. The present work revealed that it may be used as a doping substance enhancing physical and cognitive capabilities.

People are thus inclined to consume that product for feeling in excellent form. However, less accessible internet links inform that glutathione may have some adverse effects such as thoracic pain, respiratory problems, oppressive sensations, allergic reactions, skin problems, zinc deficit, and skin bleaching [www.glutathion.com/ public/gsh.htm; fr.winesino.com/diet-nutrition/nutrition/1007101201. html; www.webmd.com > Vitamins and Supplements > Reference; 
www.webmd.com/.../ingredientmono-717-glutathione.aspx?...717; www.immunehealthscience.com/glutathione-side-effects.html; https://examine.com/supplements/glutathione/].

Other sites even explain that glutathione may be dangerous for the health. [http://www.bon-coin-sante.com/blog-sante-sans-prosede-tete/le-glutathion-gsh-anti-oxudant/avis-sur-les-comprimesou-gelules-de-glutathion/\#UjY6q7r3vt4Ct4OF.99; news.abs-cbn. com > Focus]. Finally, three sites [apr-news.fr/fr/actualites/dangerdes-injections-de-glutathion-pour-se-blanchir-lapeau; https:// fraiseastucesbeautes.wordpress.com/2015/05/03/tout-savoir-sur-leglutathion/; fr.winesino.com/diet-nutrition/nutrition/1007101201. html] relate that high amount of glutathione administrated via injections lead to severe digestive problems, trembling movements, nervous spasms, anxiousness, stress, depressive state, kidney problems, blood poisoning, and skin problems leading to skin cancer. Also, some of the latter links state that the FDA (food and drug administration) has disapproved the use of glutathione injections for obtaining a clearer skin. The latter information is not easily available. Anyone only finds that glutathione is an efficient antioxidant allowing detoxification, and that its amount decreases when becoming aged or ill. This explains why many persons use that food complement and doing so, most of them effectively feel better. Is this effectively due to glutathione with not health problem occuring? The questions are thus: 'Is glutathione an excellent product, allowing feeling well? Has it no adverse effects? Does it impact the health?' Having already studied the effects of 24 substances consumed by humans, we know that the adverse effects of a product are not well known or not adequately divulgated just after its production and that research on a product is not always made without conflict of interest. We aimed thus to know the truth about glutathione by examining its ethological and physiological effects on ants used as models. Here below, we explain why we used ants as models, which species we used, what we know about it and which traits we planned to study.

\section{Why using ants as models?}

Cell functioning is similar for all animals, including humans., ${ }^{2,3}$ Most biological processes can be studied on suitable animals used as models. Physiological mechanisms, genetics, and behavior have been and are still examined using, among others, monkeys, rats, mice, parrots, cockroaches, crickets, fruit flies, mealworms, bees and so on. ${ }^{4}$ When possible, invertebrates are used because they are small, present a rapid development, and can be maintained in a laboratory in large samples. ${ }^{5}$ Insects, above all hymenoptera such as bees, are often employed. ${ }^{6}$ Ants can also be used. They are highly evolved eu-social insects. They have a unique shutting of their mouth parts, ${ }^{7}$ and many glands producing efficient pheromones. ${ }^{8}$ Their colonies present labor division, polyethism and social regulation. ${ }^{9,10}$ They build complex nests, take care of their brood, differently mark the different parts of their habitat ${ }^{9}$ and communicate thanks to informative chemical and tactile signals. ${ }^{10}$ They navigate using memorized cues, adequately recruit nestmates, clean their nest and manage cemeteries. ${ }^{9-11}$ All this allows studying on them the impacts of situations, products and environmental elements. ${ }^{11}$ Moreover, ants can be maintained, in large numbers, throughout many years, in ordinary rooms.

\section{Which species was used?}

We have largely studied ants of the genus Myrmica (their ecology, eyes, angle of vision, vision, recruitment, navigation, learning, ${ }^{12}$ ontogenesis of some of their abilities ${ }^{13}$ ). Studying the effect of electromagnetism on their learning ability and response to pheromones revealed that they could be good biological models. ${ }^{14,15}$ This was confirmed when examining, on them, the effects of alkaloids, nicotine, morphine and quinine, buprenorphine and methadone, fluoxetine, anafranil and efexor, ${ }^{16}$ paroxetine, ${ }^{17}$ carbamazepine, ${ }^{18}$ alprazolam, sweeteners, food complements and analgesics. ${ }^{19,20}$ Each time, we observed effects presented by humans, and brought novel information on them, and we revealed other effects of which humans may suffer. In present work, we used M. sabuleti Meinert 1861 for studying the potential harmful impacts of glutathione.

\section{Which traits were examined?}

We examined the effect of glutathione on 18 traits, using first ants under normal diet, secondly the same ants consuming glutathione, and after that, 4 more traits using only ants having consumed that product. The 18 traits were: meat consumption, sugar water consumption, general activity, linear speed, angular speed, orientation towards an alarm signal, following a trail, tendency in moving on an unknown apparatus, tactile ("pain") perception, caring of brood, cognitive ability, aggressive behavior against nestmates, aggressiveness against aliens, ability in escaping from an enclosure, visual conditioning ability, visual memory, olfactory conditioning ability, and olfactory memory. The 4 other traits were: adaptation to the drug consumption, habituation to the drug effect, dependence on the drug use, and vanishing of the impact of glutathione after its consumption was stopped. Adaptation exists when the adverse effects decrease over time. Habituation occurs when the beneficial affects decrease over time. Dependence appears when individuals consuming the product prefer food containing it than food free of it.

\section{Material and methods}

Most of the material and the methods here employed are identical to those used for studying the effects of different substances (see the introduction section, ${ }^{11,16-18,20}$ ). They are thus only briefly related in the novel present study.

\section{Collection and maintenance of ants}

All the experiments were performed on two colonies of $M$. sabuleti collected in the Aise Valley (Ardenne, Belgium) in June 2016, and a third colony collected the same day on the same site furnished some controls and aliens. The colonies were kept in glass tubes half filled with water and deposited in trays $(34 \mathrm{~cm} \times 2 \mathrm{~cm} \times 4 \mathrm{~cm})$, as described many times. ${ }^{17,18}$ They were fed with an aqueous solution of sugar and cut Tenebrio molitor larvae (Linnaeus, 1758). Laboratory parameters were optimum for the species..$^{17,18}$ The ants are here often named 'nestmates' as commonly do researchers on social insects.

\section{Solution of glutathione given to the ants}

A package of L-Glutathion GSH reduced ${ }^{\circledR}$ (DeBaPharma, Wevelgem), containing 60 tablets of $150 \mathrm{mg}$, was furnished by the pharmacy Wera (1170, Bruxelles, Belgium). The notice, written on the package of this food complement, invites to consume 1-3 tablets per day. Per day, humans consume about one litre of water. Thus, when consuming glutathione, they ingest per day 1- 3 tablets (the most often, 3 tablets) of the food complement together with one litre of water. Insects, and so ants, drink proportionally ten times less water than mammals. Therefore, in order to maintain the ants under a diet with glutathione similar to that of humans, they must be provided with a solution of 3 tablets of the food complement in $100 \mathrm{ml}$ water. Three tablets of L-Glutathion GSH reduced ${ }^{\circledR}$ were thus dissolved in $100 \mathrm{ml}$ of sugar water and this solution was provided to the ants in the small 
tubes commonly used for delivering them sugar water. We checked each day if ants effectively drunk the provided solution, and they did. The cotton plug shutting the tubes was refreshed every 2-3 days, and the entire solution was renewed every 7 days.

\section{Sugar water and meat consumption, general activity}

The ants drinking the sugar water, eating the T. molitor larvae, and

Table I Effect of glutathione on food consumption and general activity those being active anywhere in their environment were counted six times per day during six days, at the same times o'clock each time (Table 1, Daily counts), as we did in the course of previous works. ${ }^{11}$ We established the mean of these daily counts (Table 1, Daily means). The six daily means obtained for ants consuming glutathione were compared to those previously obtained for ants under normal diet using the non-parametric test of Wilcoxon. ${ }^{21}$ We also calculated the mean of the daily means (Table 1, Average of daily means).

\begin{tabular}{|c|c|c|c|c|c|c|}
\hline \multicolumn{4}{|c|}{ Normal diet } & \multicolumn{3}{|c|}{ Diet with glutathione } \\
\hline Days & Meat & Sugar water & Activity & Meat & Sugar water & Activity \\
\hline \multicolumn{7}{|c|}{ Daily counts } \\
\hline IA & 010221 & 111223 & 8910898 & 101110 & 111101 & 565989 \\
\hline B & 111100 & 100212 & 101110151616 & $0|0| 0 \mid$ & 222110 & 131415161716 \\
\hline II A & 100110 & 110101 & 87891010 & 100110 & 001101 & 7669109 \\
\hline B & $0|12| 1$ & 111201 & 161516111211 & 001110 & 110100 & $1413 \quad 15171817$ \\
\hline III A & 111010 & 222222 & 1098989 & 001110 & 100101 & 566879 \\
\hline B & 001222 & 221010 & 10910899 & 110211 & 111011 & 161517201820 \\
\hline IV A & 100111 & 222111 & 777898 & 100010 & 001001 & 898161213 \\
\hline B & 323222 & 333112 & $14 \mid 3 \quad 1414 \quad 1314$ & $001 \mid$ & 221100 & 161517202019 \\
\hline VA & I I0 I I I & 101011 & 556878 & 110001 & 100001 & 78811109 \\
\hline B & I0 I I I I & I I0 I I I & $1413 \quad 15101112$ & 100111 & 001111 & 101012161716 \\
\hline VIA & I I0 I | & 111332 & 556998 & 001110 & 100110 & 121312121513 \\
\hline B & 101111 & 111112 & 101110161516 & 000001 & 001001 & 181918222021 \\
\hline \multicolumn{7}{|c|}{ Daily means } \\
\hline I & 0.83 & 1.33 & 10.83 & 0.58 & 1.08 & 11.08 \\
\hline II & 0.75 & 0.83 & 11.08 & 0.5 & 0.5 & 11.75 \\
\hline III & 0.92 & 1.5 & 9 & 0.75 & 0.67 & 12.25 \\
\hline IV & 1.5 & 1.83 & 10.58 & 0.5 & 0.67 & 14.42 \\
\hline V & 0.83 & 0.75 & 9.5 & 0.58 & 0.5 & 10.92 \\
\hline $\mathrm{VI}$ & 0.58 & 1.5 & 10 & 0.33 & 0.42 & 16.25 \\
\hline \multicolumn{7}{|c|}{ Average of daily means } \\
\hline & 0.9 & 1.29 & 10.16 & 0.55 & 0.64 & 12.78 \\
\hline
\end{tabular}

During 6 days, ants eating meat, drinking sugar water, and being active were counted 6 times, and mean values were established.The food complement appeared to decrease the ants' food consumption and to increase their general activity. Details and statistics are given in the text.

\section{Speeds of locomotion and orientation ability}

As previously, ${ }^{11}$ the experiments were conducted on workers freely moving in their tray. The linear and angular speeds were quantified giving no stimulus to the ants, the orientation to an alarm signal by presenting them with a nestmate tied to a piece of white paper (Figure 2A). Such a tied worker emits its alarm pheromone issued from its mandible glands. As we did for previous works [ ${ }^{11}$ among others], for each variable, the movement of 20 ants of each colony ( $\mathrm{n}=20$ antsx 2 colonies $=40$ trajectories) was recorded on glass and was then copied on appropriate substrate which can remained affixed to a PC monitor screen due to its own static electricity charge. As previously, the recorded trajectories were analyzed using specifically designed software. ${ }^{22}$ The use of this software is explained in the latter reference, and summaries are given in previous works such as. ${ }^{17,18}$ The linear speed is the length of a trajectory divided by the time spent for making 
it. The angular speed is the sum of the angles, measured at several successive points of the trajectory, between the segment 'point $i$ to point $i-1$ ' and the following segment 'point $i$ to point $i+1$ ', divided by the length of the trajectory. The orientation to a given source point is the sum of the angles, measured at several successive points of the trajectory, between the segment 'point $\mathrm{i}$ of the trajectory - given source point' and each segment 'point $\mathrm{i}$ - point $\mathrm{i}+1$ ', divided by the number of measured angles. If the obtained value is lower than $90^{\circ}$, the animal has a tendency to orient itself towards the source point; if it is larger than $90^{\circ}$, the animal has a tendency to avoid the source point. Each distribution of 40 values was characterized by its median and quartiles (Table 2) and the distributions obtained for ants consuming glutathione were compared to those obtained for ants under normal diet, using the non-parametric $\chi^{2}$ test. $^{21}$
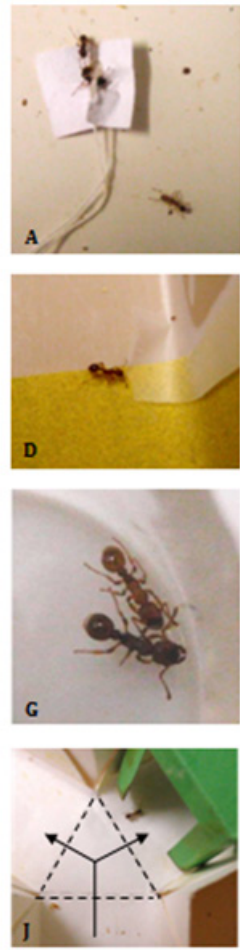
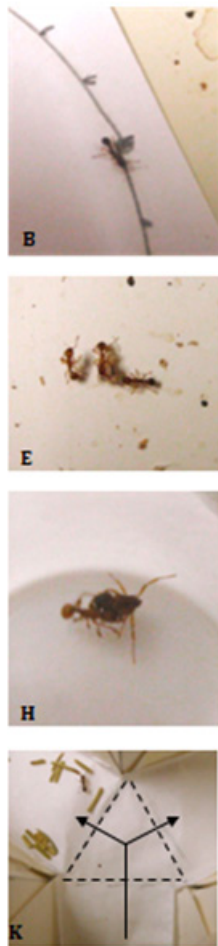
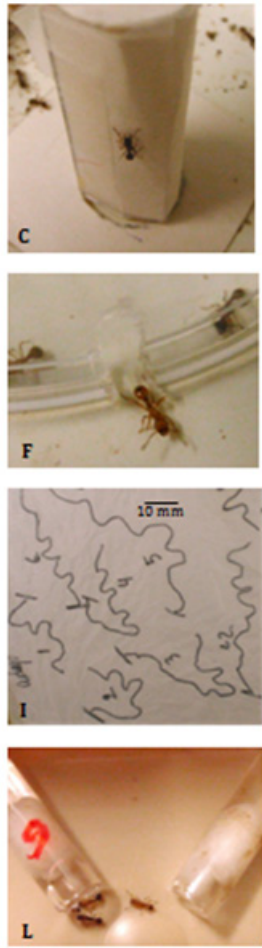

Figure 2 Some views of the experiments. All the photos are of ants living under glutathione diet. A: ants moving to a tied worker emitting its attractive alarm pheromone. B: an ant following a circular trail. C: an ant having the audacity to climb on a tower. D: an ant painfully moving on a rough substrate. $\mathrm{E}$ : ants taking care of larvae. F: an ant, staying rather calm, escaping from an enclosure. G: two nestmates gently staying side by side. $\mathrm{H}$ : an ant gripping and trying to sting an alien, in the course of an experimental dyadic encounter. I: ants' trajectories after 8 days of the food complement consumption: they were still moving quickly (each trajectory lasted only five seconds) and not very sinuously. J: an ant, trained to a green cube, giving the correct response when tested in a $Y$ apparatus provided with such a cube in one branch. $K$ an ant, trained to rosemary, giving the correct response when tested in a $\mathrm{Y}$ apparatus provided with this odorous plant in one of its branch. J, K: the arrows indicate the two possible ways. L: ants choosing sugar water containing glutathione (labeled with a ' $G$ ' in red) preferentially to the sugar water free of that food complement; the ants became somewhat addicted to the food complement.

\section{Trail following behavior}

The protocol, described in several previous works, was once more here employed. ${ }^{11,17,18,20}$ The trail pheromone of Myrmica ants is secreted by the workers' poison gland. A solution of 10 of these glands in $500 \mu 1$ of hexane was thus made and kept for $15 \mathrm{~min}$ at $-25^{\circ} \mathrm{C}$. To make an experiment, $50 \mu 1$ of the solution was deposited, thanks to a metallic normograph pen, on a circle $(\mathrm{R}=5 \mathrm{~cm})$ pencil drawn on white paper and divided into 10 angular degrees arcs. One minute later, the obtained artificial trail was deposited in the ants' tray. The response of 20 ants of each colony to that trail was assessed, as previously, by the number of arcs of 10 angular degrees the ants walked along the trail without departing from it (Figure 2B). The distribution of values was characterized by its median and quartiles (Table 2), and the distribution obtained for ants consuming glutathione was compared to that obtained for ants under normal diet using the non-parametric $\chi^{2}$ test.

Table 2 Effects of glutathione on six physiological or ethological traits.

\begin{tabular}{|c|c|c|}
\hline Traits & Normal diet & $\begin{array}{l}\text { Diet with } \\
\text { glutathione }\end{array}$ \\
\hline Linear speed (mm/s) & $13.7(\mid 2.5-14.8)$ & $17.5(15.5-19.3)$ \\
\hline $\begin{array}{l}\text { Angular speed (ang.deg./ } \\
\mathrm{cm} \text { ) }\end{array}$ & $142(129-158)$ & $128(\mid 13-142)$ \\
\hline Orientation (ang. deg.) & $36.0(29.8-49.4)$ & $40.2(32.4-52.1)$ \\
\hline Trail following ( $n^{\circ}$ arcs) & $10.0(7.0-14.0)$ & $10.0(8.0-16.0)$ \\
\hline \multirow[t]{2}{*}{ Audacity ( $\mathrm{n}^{\circ}$ ants) } & $1.05[0-2]$ & $2.10[1-3]$ \\
\hline & Tactile (pain) perception: & \\
\hline linear speed $(\mathrm{mm} / \mathrm{s})$ & $6.2(5.2-6.9)$ & $5.7(5.3-6.5)$ \\
\hline angular speed (ang.deg./cm) & $250(234-274)$ & $255(207-279)$ \\
\hline
\end{tabular}

Experimental details and statistics are given in the text. The food complement increased the ants speed of locomotion, and audacity; it did not impact their orientation, trail following and tactile (pain) perception. The ants' physiology seemed poorly affected by glutathione; they simply seemed 'to do more' under that food complement diet. mm/s: millimeter per second; ang.deg./cm: angular degree per centimeter; ang. deg.: angular degree; $\mathrm{n}^{\circ}$ arcs: number of arcs walked along the circular trail; $\mathrm{n}^{\circ}$ ants: number of ants on the unknown apparatus.

\section{Audacity}

As in several previous works, ${ }^{11,17,18,20}$ a tower made of strong white paper (Steinbach ${ }^{\circledR}$, height $=4 \mathrm{~cm}$; diameter $=1.5 \mathrm{~cm}$ ) was deposited in the ants' foraging area, and the ants present at any place of that unknown apparatus were counted 12 times over 12 min (Figure 2C). The mean and the extremes of the obtained values were established (Table 2), and the values obtained for ants under the two kinds of diet were compared to one another using the Wilcoxon test, this being done by pulling the values obtained for the two colonies as well as those obtained during each successive time period of two minutes (as in $\left.^{11}\right)$.

\section{Tactile ('pain') perception}

An ingested product may adversely impact the central as well as the sensitive nervous system. It is the reason why we assessed the ants' locomotion on a rough substrate. Indeed, ants correctly perceiving the uncomfortable character of the substrate walk with difficulties, slowly, sinuously, while ants poorly perceiving such a character walk more 
confidently, more quickly and less sinuously. As previously, ${ }_{1,17,18,20}$ a folded piece $(3 \mathrm{~cm} \times 11$ (i.e. $2+7+2) \mathrm{cm})$ of rough emery $\mathrm{n}^{\circ} 280$ paper was tied to the bottom and the borders of a tray $(15 \mathrm{~cm} \times 7 \mathrm{~cm} \times 4.5 \mathrm{~cm})$, the tray becoming so divided into a small zone $3 \mathrm{~cm}$ long, a zone $3 \mathrm{~cm}$ long where ants' moving was difficult (Figure 2D), and a $9 \mathrm{~cm}$ long smooth zone. Each colony had its own apparatus. For each of them, 12 ants were deposited in the small zone. When moving away from that small zone, the ants walked for a time on the rough paper. At that time, their speed of locomotion and their sinuosity were assessed $(n=12$ trajectoriesx 2 colonies $=24$; Table 2$)$. The values obtained for ants consuming glutathione were compared to those obtained for ants

Table 3 Impact of glutathione on five ethological or physiological traits under normal diet by using the non-parametric $\chi^{2}$ test.

\section{Caring of brood}

As previously, ${ }^{11,17,18,20}$ for each colony, larvae were removed from the nest and deposited in front of the entrance. The ants' behavior in front of five of these larvae was observed (Figure 2E), and the larvae among the five observed which were not yet replaced in the nest after $30 \mathrm{~s}, 2,4,6,8$, and $10 \mathrm{~min}$ were counted. The results obtained for each colony were pulled (Table 3), and the sums obtained for ants under glutathione diet were compared to those obtained for ants under normal diet using the non-parametric Wilcoxon test.

\begin{tabular}{|c|c|c|}
\hline Traits & Normal diet & Diet with glutathione \\
\hline \multirow[t]{2}{*}{$\begin{array}{l}\text { Brood caring: } \mathrm{n}^{\circ} \text { of larvae among } 10 \text { not replaced in the } \\
\text { nest in the course of } 10 \mathrm{~min}\end{array}$} & $\mathrm{t}: 30 \mathrm{~s} 246810 \mathrm{~min}$ & t: $30 \mathrm{~s} 246810 \mathrm{~min}$ \\
\hline & $\mathrm{n}^{\circ} 1086420$ & $\mathrm{n}^{\circ} 1086420$ \\
\hline \multirow[t]{9}{*}{$\begin{array}{l}\text { Cognition: ants in front of and beyond twists and turns in } \\
\text { the course of } 12 \mathrm{~min}\end{array}$} & $\mathrm{t}^{\circ}$ in front $\mathrm{n}^{\circ}$ beyond & $\mathrm{t}^{\circ}$ in front $\mathrm{n}^{\circ}$ beyond \\
\hline & 30 s 300 & $30 s 250$ \\
\hline & 2190 & $217 \mid$ \\
\hline & $4|4|$ & 4132 \\
\hline & 6142 & 6114 \\
\hline & 8133 & 887 \\
\hline & 10114 & 1097 \\
\hline & 12105 & 1287 \\
\hline & levels 0 I 234 var 'a' & levels 0 I 234 var 'a' \\
\hline \multirow{2}{*}{ Aggressiveness against nestmates } & $n^{\circ} 753812000.10$ & $n^{\circ} 534015000.16$ \\
\hline & levels 0 I 234 var 'a' & levels 0 I 234 var 'a' \\
\hline \multirow{2}{*}{ Aggressiveness against aliens } & $n^{\circ} 3334144194.75$ & $n^{\circ} 17215262393.90$ \\
\hline & t: $30 \mathrm{~s} 24681012$ & t: $30 \mathrm{~s} 24681012$ \\
\hline \multirow{3}{*}{$\begin{array}{l}\text { Escaping from an enclosure: ants in and out of the } \\
\text { enclosure in the course of } 12 \mathrm{~min}\end{array}$} & $n^{\circ}$ in 11986533 & $n^{\circ}$ in : 121086533 \\
\hline & $\mathrm{n}^{\circ}$ out: I 346799 & $\mathrm{n}^{\circ}$ out: 0246799 \\
\hline & variable $=9 / 12=0.75$ & variable $=9 / 12=0.75$ \\
\hline
\end{tabular}

See the text for statistics and experimental details. Glutathione did not impact the ants' brood caring, the relationships with nestmates or aliens, and the escaping behavior thus the state of stress. It enhanced the insects' cognition. These results are in agreement with previous ones (Tables I \& Table 2): under glutathione diet, ants' physiology seemed intact, but these insects 'can do more'. s: second; min: minute; $\mathrm{n}^{\circ}$ : number of ants; levels 0 : doing nothing, I: contacting the opponent with antennae, 2: opening the mandibles, 3: gripping the opponent, 4: stinging or trying to sting the opponent; variable: number of ants escaping / 12.

\section{Cognition}

The protocol was set up when studying the effects of nicotine..$^{23}$ Two folded pieces of white strong paper (Steinbach ${ }^{\circledR}, 12 \mathrm{~cm} \times 4.5 \mathrm{~cm}$ ) were inserted in a tray $(15 \mathrm{~cm} \times 7 \mathrm{~cm} \times 4.5 \mathrm{~cm})$ for creating a path with twists and turns between an initial small loggia and a large one. Each colony had its own apparatus. For each of them, 15 ants were set all together in the initial loggia, and just after, the ants present in this initial loggia and in the large one were counted after $30 \mathrm{~s}, 2,4,6,8$, 10 and $12 \mathrm{~min}$. The numbers obtained for the two colonies were added (Table 3), and the sums obtained for ants consuming glutathione were compared to those obtained for ants under normal diet using the nonparametric Wilcoxon test.

\section{Aggressive behavior against nestmates and aliens}

This treat was assessed as in previous studies [ ${ }^{11}$,among others]. Five dyadic encounters with a nestmate and with an alien were realized for each colony. Each encountering was conducted in a small cylindrical cup (diameter $=2 \mathrm{~cm}$, height $=1.6 \mathrm{~cm}$ ), the borders of which being slightly covered with talc. Each time $(5 \times 2=10$ encounters with nestmates, $5 \times 2=10$ encounters with aliens), one ant of colony A or B was observed during $5 \mathrm{~min}$ and its encounter with the opponent was characterized, as previously, by the number of times it did nothing (level 0 of aggressiveness), touched the other ant with its antennae (level 1), opened its mandibles (level 2), gripped and/or pulled the other ant (level 3), tried to sting or stung the other ant (level 4) (Figure 
$2 \mathrm{G}, \mathrm{H})$. The numbers recorded for the two colonies were added (Table 3), and the results obtained for ants under glutathione diet were compared to those obtained for ants under normal diet using the non-parametric $\mathrm{X}^{2}$ test. As in previous works [ ${ }^{11}$,for instance], the ants' aggressiveness was also quantified by ' $a$ ', equaling the number of recorded aggressiveness levels $2+3+4$ divided by the number of recorded levels $0+1$.

\section{Escaping from an enclosure}

For each colony, six ants were enclosed in a reversed polyacetate glass $(\mathrm{h}=8 \mathrm{~cm}$, bottom diameter $=7 \mathrm{~cm}$, ceiling diameter $=5 \mathrm{~cm})$ set in the ants' foraging area. Details are given in previous works. ${ }^{11,17,18,20}$ The rim of the bottom of the glass was provided with a small notch ( $3 \mathrm{~mm}$ height, $2 \mathrm{~mm}$ broad) for giving to the ants the opportunity of escaping from the enclosure (Figure 2F). To quantify such ability, the ants still under the glass and those escaped after $30 \mathrm{~s}, 2,4,6,8,10$ and $12 \mathrm{~min}$ were counted. The results obtained for the two colonies were added (Table 3 ), and the sums obtained for ants consuming glutathione were compared to those obtained for ants under normal diet using the non-parametric Wilcoxon test. We also evaluated the ants' ability in escaping by the variable " $\mathrm{n}^{\circ}$ of ants escaped after $12 \mathrm{~min} / 12$ " (Table $3)$.

\section{Visual, olfactory conditioning and memory}

The protocol of these experiments have been set up many years ago and used several times [among others in..$^{11,17,18,20}$ Here, we used it again for approaching the effect of glutathione on learning and memorizing capabilities, experimenting on colonies A and B which consumed the food complement, and using results previously obtained on colony $\mathrm{C}$ never provided with glutathione [work on statins, in press]. At a given time, a green hollow cube under which the ants could go was set above the entrance of the sugar water tube, the ants undergoing so visual operant conditioning. One week later, after the end of that visual conditioning experiment, pieces of rosemary were deposited all around the entrance of the sugar water tube, the ants undergoing then olfactory operant conditioning. Tests were performed over time, while ants acquired conditioning, and after removal of the cue, while they lost it. The ants were individually tested in a Y-apparatus constructed of strong white paper, and set in a small tray $(30 \mathrm{~cm} \times 15 \mathrm{~cm} \times 4 \mathrm{~cm})$, as explained in previous studies..$^{11,17,18,20}$ The Y-apparatus was provided with a green hollow cube or pieces of rosemary in one branch. Half of the tests were conducted with the cue in the left branch and the other half with the cue in the right branch. Moving into the branch containing the cue was considered as giving the correct response (Figure 2J, K). For each test, 10 ants of each colony were tested, the numbers of ants under glutathione diet being thus 10 ants 2 colonies $=20$ ants, and of ants under normal diet, $\mathrm{n}=10$. The percentage of correct responses was established for each test (Table 4). The numerical results obtained for ants under one and the other diet were compared thanks to the nonparametric Wilcoxon test.

\section{Adaptation to glutathione consumption}

After the ants lived under a diet with glutathione during 8 days, their linear speed was again assessed in the manner they had been before consuming the food complement and after they had consumed it for one day, in order to examine if ants went on walking rapidly or if they became adapted to the glutathione effect on their locomotion (Table 5, Figure 2I). The distribution of values obtained after 8 days of glutathione consumption were compared to the control one and to that obtained after one day of that food complement consumption using the non-parametric $\chi^{2}$ test.
Table 4 Impact of glutathione on ants' conditioning ability and memory

\begin{tabular}{|c|c|c|c|c|c|}
\hline \multirow{2}{*}{$\begin{array}{l}\text { Traits } \\
\text { time(H) }\end{array}$} & \multicolumn{2}{|c|}{ Under normal diet * } & \multicolumn{3}{|c|}{ Under glutathione diet } \\
\hline & colony C & $\%$ & colony A & colony B & $\%$ \\
\hline \multicolumn{6}{|l|}{24} \\
\hline 7 & 7 & 70 & 7 & 5 & 65 \\
\hline 24 & 8 & 80 & 7 & 7 & 70 \\
\hline 31 & 8 & 80 & 8 & 8 & 75 \\
\hline 48 & 8 & 80 & 10 & 8 & 80 \\
\hline 55 & 8 & 80 & 8 & 9 & 85 \\
\hline 72 & 8 & 80 & 9 & 9 & 90 \\
\hline \multicolumn{6}{|c|}{ Visual memory } \\
\hline 7 & 8 & 80 & 9 & 9 & 90 \\
\hline 24 & 7 & 70 & 9 & 9 & 90 \\
\hline 31 & 8 & 80 & 8 & 8 & 80 \\
\hline 48 & 7 & 70 & 9 & 9 & 90 \\
\hline 55 & 7 & 70 & 9 & 8 & 85 \\
\hline 72 & 7 & 70 & 8 & 8 & 80 \\
\hline \multicolumn{6}{|c|}{ Olfactory conditioning } \\
\hline 7 & 7 & 70 & 8 & 8 & 80 \\
\hline 8 & 8 & 80 & 9 & 9 & 85 \\
\hline 8 & 8 & 80 & 8 & 10 & 90 \\
\hline 9 & 9 & 90 & 8 & 9 & 85 \\
\hline 9 & 9 & 90 & 9 & 9 & 90 \\
\hline 9 & 9 & 90 & 10 & 8 & 90 \\
\hline \multicolumn{6}{|c|}{ Olfactory memory } \\
\hline 7 & 9 & 90 & 9 & 10 & 95 \\
\hline 8 & 8 & 80 & 9 & 9 & 90 \\
\hline 8 & 8 & 80 & 8 & 8 & 80 \\
\hline 9 & 7 & 70 & 9 & 10 & 95 \\
\hline 9 & 8 & 80 & 9 & 9 & 90 \\
\hline 9 & 8 & 80 & 10 & 9 & 95 \\
\hline
\end{tabular}

Ants were trained to a visual, then to an olfactory cue. Each time, they were tested in a $Y$ apparatus in the course of their conditioning acquisition, and after removal of the cue, of their conditioning loss, the latter tests assessing their memory. Glutathione did not impact the ants' ability in acquiring conditioning, as well as their memory, on the contrary, it slightly enhanced these traits, what was in agreement with previous results (Tables I-3). h: hours; \%: percentage; *: results reviously obtained while studying the effects of statins [in press].

\section{Habituation to glutathione consumption}

After the ants consumed glutathione since 9 days, their audacity (increased by that food complement) was again quantified in the manner it had been before the ants consumed glutathione and after they had consumed it for 3 days, in order to know if ants became habituated to the impact of the food complement on their straightforwardness (Table 5). The numerical results obtained after 9 days of consumption were compared to the control ones and to those obtained after 3 days of consumption using the non-parametric Wilcoxon test. 
Table 5 Ants adaptation and habituation to the effects of glutathione.

\begin{tabular}{llll}
\hline Traits, variables & Normal diet & I-3 Days glutathione diet & 8-9 Days glutathione diet \\
\hline Adaptation linear speed $(\mathrm{mm} / \mathrm{s})$ & $13.7(12.5-14.8)$ & $17.5(15.5-19.3)$ & $19.2(15.6-19.9)-$ \\
Habituation audacity $\left(\mathrm{n}^{\circ}\right.$ ants $)$ & $1.05[0-2]$ & $2.10[1-3]$ & $2.35[1-4]$ \\
\hline
\end{tabular}

Upper part: the ants linear speed was assessed while they lived under normal diet, when they had consumed glutathione for one day, and after they had done so for 8 days; the effect of the food complement persisted over its consumption. Lower part: the ants' audacity was assessed while they lived under normal diet, when they had consumed glutathione for 3 days, and after they had done so for 9 days; the effect of the food complement persisted over its consumption. There was thus no adaptation and no habituation to glutathione. $\mathrm{mm} / \mathrm{s}$ : millimeter per second; $\mathrm{n}^{\circ}$ ants: mean [and extremes] numbers of ants on an unknown apparatus.

\section{Dependence on glutathione consumption}

After the ants lived under a glutathione diet during 18 days, we conducted an experiment in order to reveal if they became dependent on that food complement consumption. The protocol of this experiment was identical to that used for examining potential ants' addiction to different substances [for instance, ${ }^{11,17,18,20}$ For colony A and for colony B, 15 ants were removed and set in a small tray $(15 \mathrm{~cm} \times 7 \mathrm{~cm} \times 5 \mathrm{~cm})$ in which two tubes $(\mathrm{h}=2.5 \mathrm{~cm}$, diam. $=0.5 \mathrm{~cm})$ had been deposited, one containing sugar water, the other containing a sugar solution of glutathione i.e. the solution used throughout the hole study (Figure $2 \mathrm{~L}$ ). In one tray, the tube containing the food complement was deposited on the right, and in the other tray, it was deposited on the left. After that, the ants seen drinking each liquid were counted 15 times over $15 \mathrm{~min}$. The two sums of these two different counts were compared to those which should have been obtained if ants randomly went drinking each kind of provided liquid, using the non-parametric goodness of fit $\chi^{2}$ test. ${ }^{21}$ On the basis of these two sums, we also established the proportion of ants which have chosen each kind of liquid. Thereafter, we made an identical experiment on ants of colony $\mathrm{C}$ (which had never received glutathione) in order to confirm or infirm our deduction.

\section{Loss of the effects of glutathione after its consumption was stopped}

The protocol of such a study is detailed in previous works [for instance, $\left.{ }^{11}\right]$. A fresh solution of glutathione was provided to the ants 12 hours before the start of the present experiment which began just when that solution of glutathione was replaced by an aqueous solution of sugar, free of the food complement. Since that weaning time, the ants' linear speed was assessed just like it had been before the ants consumed the food complement, after they had consumed it for one day and after they had consumed it for 8 days, except that 20 instead of 40 ant's trajectories were recorded for being able to make the assessments in the course of the experimentation. These assessments were performed after several time periods. The obtained numerical results were compared to those obtained after one day of glutathione consumption $(\mathrm{t}=0)$ and to the control ones, using the two latter values as control groups in a non-parametric Kruskal-Wallis ANOVA for multiple comparisons. ${ }^{21}$ The non-parametric $\chi^{2}$ test was also used for comparing some distributions. All tests were one-tailed. The results of the present experiment are given in Table 6, and are graphically presented in (Figure 3). The experiment ended when the ants' linear speed became similar to that presented under normal diet.

Table 6 Decrease of the effect of glutathione after its consumption was stopped

\begin{tabular}{|c|c|c|c|}
\hline Experiment & Linear speed $(\mathbf{M m} / \mathbf{S})$ & Compared $\mathrm{To} T=0$ & Compared to normal diet \\
\hline Under glutathione diet & $17.5(15.5-19.3)$ & & \\
\hline \multicolumn{4}{|c|}{ Time periods after weaning $(\mathrm{h})$} \\
\hline $\mathrm{t}=0$ & $17.4(15.6-10.2)$ & & $P<0.0002 ; S$ \\
\hline$t=2$ & $17.4(15.8-19.9)$ & $P=1 ; N S$ & $P<0.0002 ; S$ \\
\hline $\mathrm{t}=4$ & $15.8(\mid 3.3-18.4)$ & $P=0.43 ; N S$ & $P=0.0256 ; S$ \\
\hline$t=51 / 2$ & $14.7(\mid 3.5-16.8)$ & $P=0.11 ; N S$ & $P=0.16 ; N S$ \\
\hline$t=7$ & $14.3(13.8-15.6)$ & $P=0.0176 ; S$ & $P=0.80 ; N S$ \\
\hline$t=81 / 2$ & $13.4(\mid 1.2-14.4)$ & $P<0.0002 ; S$ & $P=I ; N S$ \\
\hline$t=10$ & $11.6(10.2-12.6)$ & $P<0.0002 ; S$ & $P=0.02(S$, lower $)$ \\
\hline $\mathrm{t}=121 / 2$ & $13.7(12.2-15.6)$ & $P=0.0008 ; S$ & $P=1 ; N S$ \\
\hline Under normal diet & $13.7(|2.5-| 4.8)$ & & \\
\hline
\end{tabular}

After having stayed intact for two hours, the effect of glutathione on the ants' linear speed (column 2, median (quartiles)) rapidly decreased in about five hours (= until about seven hours after weaning), this rapid decrease being followed by a recovering period of about four hours. The numerical values of linear speed over time are graphically presented in (Figure 3). $\mathrm{mm} / \mathrm{s}$ : millimeter/second; t: time, h: hour; P: level of probability; results of Kruskal-Wallis one-tailed tests for multiple comparisons, taking the values obtained at $\mathrm{t}=0$ (column 3 ) and those from ants under normal diet (column 4 ) as control groups. 


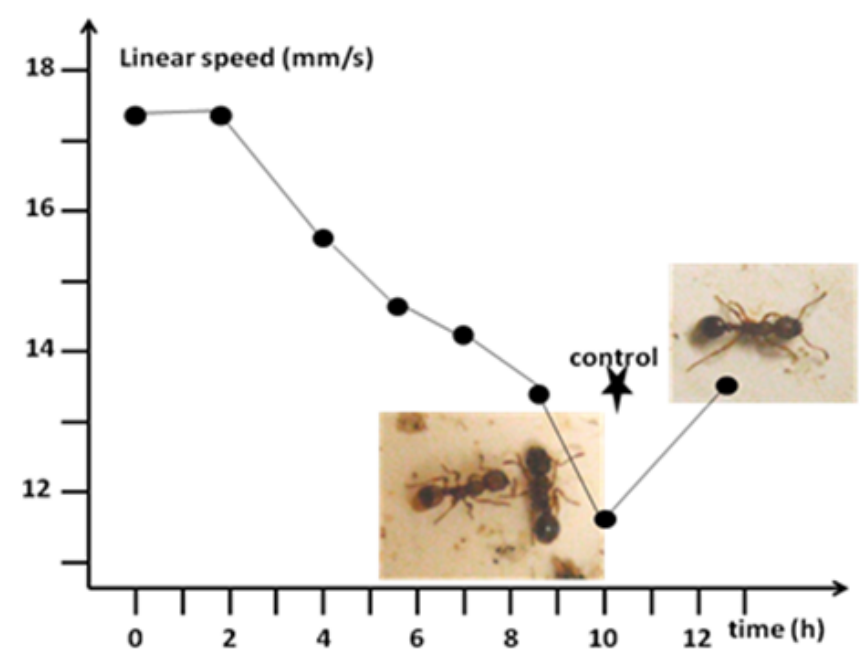

Figure 3 Decrease of the effect of glutathione after weaning. The numerica values of linear speed are given in (Table 6), and the function of the decrease from 2 until 10 hours after weaning is given in the text. After the end of its consumption, glutathione rapidly lost its effect since $2-2 \frac{1}{2}$ to $7-71 / 2$ hours after weaning, what was followed, about since 8 until 12 hours after weaning, by a recovering period. All this may incite consuming again the food complement and may finally lead to dependence on it.

\section{Results and discussion}

\section{Sugar water and meat consumption, general activity}

These physiological traits were affected by glutathione consumption (Table 1). Under that food complement diet, the ants eat less meat food as well as less sugar water than when under normal diet, and this observation was statistically significant (meat: $\mathrm{N}=6, \mathrm{~T}=-$ 21 , $\mathrm{P}=0.016$; sugar: $\mathrm{N}=6, \mathrm{~T}=-21, \mathrm{P}=0.016$ ). On the contrary, the ants' general activity was increased by the consumption of glutathione. Indeed, under that food complement diet, the ants were statistically more active than when living under normal diet $(\mathrm{N}=6, \mathrm{~T}=-21$, $\mathrm{P}=0.016$ ), and this was obvious while caring of the ants. The averages of the daily means of the counted numbers of ants clearly pointed out these physiological effects of glutathione: meat consumption: 0.55 vs 0.90 , sugar consumption: 0.64 vs 1.29 , general activity: 12.78 vs 10.16. Such an increase of activity together with less ingestion of food looked like what occurs under doping, but this presumption had still to be submitted to experimentation throughout the present work.

\section{Linear and angular speeds of locomotion}

Glutathione impacted these physiological traits (Table 2, lines $1,2)$. Indeed, under this food complement diet, ants walked more quickly and less sinuously than when under normal diet. This was obvious while looking to the ants, and was confirmed by the obtained numerical values and the statistical analysis (linear speed: $\chi^{2}=29.89$, $\mathrm{df}=2, \mathrm{P}<0.001$; angular speed: $\left.\chi^{2}=11.55, \mathrm{df}=3,0.001<\mathrm{P}<0.01\right)$. The fact that the ants' sinuosity did not increase, and even somewhat decreased, accounted for a not excited state of the ants: they did not move erratically, but simply more rapidly. This result was in agreement with the previous one, i.e. an increase of the general activity, corroborating so our first presumption.

\section{Orientation to an alarm signal}

This physiological and ethological trait was not affected by glutathione consumption (Table 2, line 3; Figure 2A). This was obvious while experimenting and was confirmed by the obtained numerical results and their statistical analysis. Indeed, the values corresponding to ants under glutathione diet did not statistically differ from those corresponding to ants under normal diet $\left(\chi^{2}=1.31, \mathrm{df}=2\right.$, $0.50<\mathrm{P}<0.70$ ). Consequently, glutathione did not impact the ants' olfactory perception as well as their ability in orienting themselves towards a given source, two deductions again thought about after several following experiments (see below).

\section{Trail following behavior}

This ethological trait, depending on olfactory perception and pheromonal signal recognizing, was not affected by glutathione consumption (Table 2, line 4; Figure 2B). Indeed, ants consuming this food complement followed a circular trail as well as ants living under normal diet, i.e. each time along meanly 10 arcs of 10 ang. deg. The difference of behavior between ants under the two kinds of diet was not significant $\left(\mathrm{X}^{2}=0.30, \mathrm{df}=2,0.80<\mathrm{P}<0.90\right)$. The deduction of this result confirmed that of the here above result, i.e. the non impact of glutathione on ants' olfactory perception and knowledge of social signals.

\section{Audacity}

Glutathione enhanced this ethological trait (Table 2, line 5; Figure 2C), an obvious observation confirmed by statistically significant results. Under that food complement diet, the ants were more inclined to come onto the provided unknown apparatus, and several ones even climbed up to the top of the tower. The numbers of ants counted on the apparatus, while living under one or the other kinds of diet, statistically differed: $\mathrm{N}=5, \mathrm{~T}=+15, \mathrm{P}=0.031$. This result was in agreement with two previous ones, i.e. increase of general activity, increase of speed of locomotion, and reinforced the presumption that glutathione might act as a doping substance.

\section{Tactile ('pain') perception}

This physiological trait was not affected by glutathione consumption (Table 2, line 6; Figure 2D). This was obvious to the observer and was confirmed by the obtained values of ants' linear and angular speeds on a rough substrate, as well as by the statistical analysis of these values. Indeed, the values obtained for ants under one and the other kinds of diet did not statistically differ (linear speed: $\mathrm{X}^{2}=0.51, \mathrm{df}=1,0.30<\mathrm{P}<0.50$; angular speed: $\mathrm{X}^{2}=0.60, \mathrm{df}=2$, $0.70<\mathrm{P}<0.80$ ). Under glutathione diet, ants kept thus intact their tactile perception, what was in agreement with the fact that they kept their olfactory perception (see above 'Orientation towards an alarm signal' and 'Trail following behavior'). Note that, contrary to drugs such as cocaine or morphine, doping substances generally do not alter the individuals' perception and cognitive abilities. Indeed, humans may consume such substances before an exam or a competition, a challenge requiring excellent visual or auditory perception as well as intact cognitive abilities. Glutathione might thus act like a doping substance, as presumed above and examined in following experiments (see below).

\section{Brood caring behavior}

Glutathione did not impact this ethological trait (Table 3, line 1; Figure 2E). Ants consuming that food complement took care of their brood just like while living under normal diet, and replaced in the nest larvae experimentally removed from it, as quickly, as efficiently. The difference of behavior between ants consuming or not glutathione was not significant $(\mathrm{N}=0, \mathrm{NS})$. The food complement may thus not 
affect the individuals' relationship with members of their colony, a hypothesis tested in a subsequent experiment (see below 'Aggressive behavior against nestmates'). The present result was in agreement with that on the ants' orientation. Indeed, in the present experiment, the ants could well perceive the larvae and orient themselves towards the nest entrance and in the experiment relative to the orientation, the ants could well perceive the attractive alarm pheromone and orient themselves towards its source.

\section{Cognition}

This physiological and ethological trait was enhanced by glutathione consumption (Table 3, line 2). Under normal diet, 5 ants among 30 could cross the twists and turns path and reach the large loggia located beyond, while 10 ants were still in the small loggia in front of the difficult path, at the end of the 12 experimental minutes. When living under glutathione diet, 7 ants could reach the large loggia and 8 ones were still in the small loggia in the course of the same time period. The difference of ants' performance according to their diet was significant: small loggia: $\mathrm{N}=7, \mathrm{~T}=-28, \mathrm{P}=0.008$; large loggia: $\mathrm{N}=6, \mathrm{~T}=+21, \mathrm{P}=0.016$ ). This result could be explained by previous observations: under glutathione diet, the ants walked more rapidly and were more inclined to make a risky task than when under normal diet. The present result also showed that the food complement did not impact, on the contrary, the ants' cognitive abilities. The latter deduction was again checked by a following experiment (see below 'Visual and olfactory conditioning').

\section{Aggressive behavior against nestmates and aliens}

These ethological traits were not impacted by glutathione consumption (Table 3, lines 3,4). In front of a nestmate, ants under that food complement diet as well as ants under normal diet never became aggressive. They simply did nothing, or touched the opponent with their antennae, or slightly opened their mandibles (Figure $2 \mathrm{G}$ ). The difference of behavior between ants under the two kinds of diet was not significant $\left(\chi^{2}=5.17, \mathrm{df}=2,0.05<\mathrm{P}<0.10\right)$. However, ants under glutathione diet less often stayed doing nothing, and somewhat more often contacted the opponent with their antennae and opened their mandibles. This was pointed out by the variable assessing the ants' aggressiveness against nestmates, which equaled 0.16 for ants under glutathione diet and 0.10 for those under normal diet. This was also in agreement with a previous result: glutathione increased the ants' general activity. In front of an alien, ants under glutathione diet as well as ants under normal diet quickly became aggressive (Figure $2 \mathrm{H})$. They often opened their mandibles, gripped the opponent and even stung or tried to sting it. There was no difference between the aggressiveness of ants living under one or the other kinds of diet ( $\chi^{2}=1.83, \mathrm{df}=3,0.50<\mathrm{P}<0.70$ ): the number of gripping and stinging observed among all the recorded behaviors equaled $36+14=50 / 101$ for ants under glutathione diet, and $44+29=73 / 150$ for ants under normal diet, which were identical proportions. However, under glutathione diet, ants generally run around the opponent before attacking, during a longer time than when under normal diet (number of ants doing so: 17 vs 3), doing then 'nothing', what was pointed out by the variable assessing their aggressive behavior, a variable equaling 3.90 for ants under glutathione diet and 4.75 for ants under normal diet, and this was in agreement with an increase of general activity under glutathione diet (see above). In conclusion, even if very few differences existed between ants under normal and glutathione diet as for their behavior in front of a nestmate and an alien (these differences resulting from a higher activity of ants under glutathione diet), glutathione consumption obviously did not affect the ants' relationship with their nestmates and aliens. This result was in agreement with that relative to the ants' brood caring behavior (see above).

\section{Escaping from an enclosure}

Glutathione did not affect this ability (Table 3, last line; Figure 2F). Under normal diet, 9 ants among 12 could escape from the enclosure in the course of the 12 experimental minutes, 3 ones being thus still enclosed, and the variable assessing the ants' escaping behavior equaling 0.75 . The same score was reached by ants consuming glutathione: 9 ants escaped, 3 still enclosed. The difference between ants' behavior according to their kind of diet was not significant (for ants escaped as well as for those still enclosed: $\mathrm{N}=2$, NS). There was however a very slight difference between ants under one and the other kinds of diet: while consuming glutathione, the ants walked quickly everywhere during the first two experimental minutes, and their score in escaping during these two first minutes was then lower than that of ants under normal diet. Thereafter, ants consuming glutathione perfectly walked (rather quickly) all along the rim of the enclosure and escaped efficiently. They were also helped by ants already escaped and by a few ones moving on the foraging area which came in front of the exit and very probably emitted their attractive alarm pheromone. As a matter of fact, such a result confirmed previous observations: glutathione did not impact, on the contrary, the ants' cognitive abilities, and somewhat increased their locomotion. The former observation was again submitted to experimentation by examining the effect of the food complement on the ants' conditioning ability (see below). The present result also showed that glutathione did not lead to stress, excited state, or anxiousness since under such a physiological state, the ants' escaping behavior is somewhat decreased. ${ }^{24}$

\section{Visual and olfactory conditioning and memory}

These traits were not impacted or slightly enhanced by glutathione consumption (Table 4, Figure 2J,K). Concerning the visual conditioning, under normal diet, the ants acquired a score of $70 \%$ after $7 \mathrm{~h}$ and of $80 \%$ after $72 \mathrm{~h}$ of training. Under a diet with glutathione, they acquired a score of $65 \%$ and of $90 \%$ after the same time periods of training. The difference of ability in acquiring conditioning between ants living under each kind of diet was not significant $(\mathrm{N}=5$, $\mathrm{T}=+9.5, \mathrm{P}=0.359$ ). In fact, ants consuming glutathione acquired their conditioning a little more slowly and reached finally a higher score, what is in accordance with the brain functioning (i.e. the more rapidly a learning is acquired, the less is finally retained by the brain). Seven hours after removal of the visual cue, ants under normal diet as well as those under glutathione diet still presented their acquired score (that is $80 \%$ for the former ants and $90 \%$ for the latter ones). After 72 hours, ants under glutathione and normal diet made a score of $80 \%$ and $70 \%$ respectively. The difference of visual memory between ants living under the two kinds of diet was significant $(\mathrm{N}=5, \mathrm{~T}=+15, \mathrm{P}=0.031)$. All this confirmed previous deductions: glutathione did not impact the ants' learning capabilities and their memory, thus their cognitive abilities; on the contrary, it may slightly enhance them.

Concerning the olfactory conditioning, we have not collected data during the first 6 hours of training and thus did not know if ants under glutathione diet started to be conditioned earlier than those under normal diet. After 7 hours of training, ants under the food complement diet had reached a conditioning score of $80 \%$, while those under normal diet presented a score of $70 \%$. After 72 hours of training, the ants under glutathione as well as under normal diet responded with a score of $90 \%$. The difference of ability in acquiring 
olfactory conditioning between ants under one and the other kind of diet was not significant $(\mathrm{N}=4, \mathrm{~T}=+6.5, \mathrm{P}=0.375)$. Seven hours after removal of the pieces of rosemary, the ants under glutathione diet responded with a score of $95 \%$, and those under normal diet with a score of $90 \%$. After having no longer perceived that olfactory cue, ants under glutathione and those under normal diet presented a score of $95 \%$ and $80 \%$ respectively. The difference of olfactory memory between ants under the two kinds of diet was significant $(\mathrm{N}=5, \mathrm{~T}=+15$, $\mathrm{P}=0.031$ ). Such a result showed that glutathione did not affect, and even enhanced the ants' short and middle term memory, what was in agreement with previous deductions, i.e. the food complement did not impact the individuals' cognitive abilities and even somewhat ameliorated them .

\section{Adaptation to glutathione consumption}

While looking to the ants, days after days over their life under glutathione diet, we could not but presume that they never become adapted to the effect of that food complement on their speed of locomotion. Assessing the latter trait after 8 days of glutathione consumption confirmed this consumption. Indeed, numerical results and statistical analysis pointed out that, effectively, the ants' speed of locomotion after 8 days of consumption still differed from their control one ( $\chi^{2}=32.41 \mathrm{df}=2, \mathrm{P}<0.001$ ), and was statistically similar to that presented after one day of consumption $\left(\chi^{2}=2.70 \mathrm{df}=2\right.$, $0.20<\mathrm{P}<0.30$ ), being even somewhat larger (Table 5, upper part; Figure 2I). It can thus be deduced that glutathione kept its effect, i.e. did not progressively lost it, all over its consumption. Humans consuming that food complement should perceive such a persistent effect, and should not be inclined to consume more and more glutathione over time.

\section{Habituation to glutathione consumption}

Was glutathione keeping intact its effect on ants' audacity in the course of its consumption? An experiment devoted to the assessment of this trait was again performed after 9 days of the food complement consumption. The numerical results, the statistical analysis, and the observation of the reacting ants obviously showed that the ants' audacity remained impacted by glutathione after 9 days of consumption (Table 5, lower part). At that time, the ants' audacity still differed from the control one $(\mathrm{N}=5, \mathrm{~T}=+15, \mathrm{P}=0.031)$, and was statistically similar to that presented after 3 days of glutathione consumption $(\mathrm{N}=3, \mathrm{~T}=+6, \mathrm{P}=0.125)$, being even somewhat larger. Consequently, glutathione did not lose its effects over its consumption, what could be felt by consumers, who therefore should not increase their ingested amount, a deduction in agreement with that of the previous experiment (see above). Until now, we found that glutathione has some adverse effects, but also several valuable favourable effects. This is in agreement with the statement given in most easily available internet sites on glutathione (see the introduction section), and with the authors explaining the use of that food complement for caring of ill persons [f.i. 25-34, visited 100-400 times]. However, on basis of our results, we could presumed that glutathione may be used as a doping substance.

\section{Dependence on glutathione consumption}

Briefly, some dependence occurred for glutathione consumption (Figure 2L). While experimenting, it appeared obvious that ants had a tendency to go preferentially on the liquid containing the food complement. The numerical results confirmed this observation.
Indeed, in the course of the 15 counting, 5 ants of colony A were seen on the liquid free of glutathione and 23 ones on that containing the food complement, while 15 ants of colony B were seen on the liquid containing glutathione and 8 ones on that free of the food complement. In total, 38 ants went on the liquid containing glutathione and 13 ones on that free of the food complement. This represented $25.5 \%$ of individuals choosing the liquid free of glutathione and $74.5 \%$ preferring the liquid containing the food complement. These numbers of ants statistically differed from those expected if ants went randomly drinking each provided liquid (25.5 and 25.5) ( $\chi^{2}$ $=5.70, \mathrm{df}=1,0.01<\mathrm{P}<0.02)$. Consequently, ants developed some dependence on glutathione consumption, a slight addiction humans may acquire, becoming aware of the favorable effect of that food complement on their physical and cognitive performances. However, glutathione might have a pleasant taste for the ants. Therefore, as a precaution, a control experiment was performed on ants of colony $\mathrm{C}$ using exactly the same protocol. In the course of the 15 counting, 23 ants of colony $\mathrm{C}$ were counted on the liquid containing glutathione and 38 ones on that free of the food complement. This corresponded to $37.7 \%$ of ants choosing the liquid with glutathione and $62.3 \%$ of ants choosing the liquid free of the food complement. The statistical analysis of the numerical results $(23,38)$ revealed that they did not differ from those expected if ants randomly went drinking each kind of liquid $(30.5,30.5)\left(\chi^{2}=0.70, \mathrm{df}=1,0.30<\mathrm{P}<0.50\right)$. Consequently, ants having never had glutathione in their sugar water did not preferentially consume liquid containing the food complement, on the contrary ( 23 vs 38 ). This result confirmed our previous deduction: the acquisition, by ants having 'known' glutathione, of some addiction to that food complement which might be used as a doping substance. After having completed this experiment and had the presumption of a possible addiction to glutathione and of its use as a doping substance, we discovered a not easily available internet site [35, visited 4,000 5,000 times] stating such a possible addiction and use. Our results and deduction were thus in agreement with the statement of the latter site, and consequently not entirely (but only partly) with the authors affirming that glutathione has no adverse effects (see the introduction section).

\section{Decrease of the effects of glutathione after its consumption was stopped}

Glutathione 'sensu stricto' has a half-live of only 1.6 minute. The commercialized product is in fact an 'acetly-glutathione', the radical 'acetyl' being linked to the 'S' (active part) of glutathione (Figure 1). Under that acetyl form, the compound can reach each cell through the intestine and the blood circulation. The different internet links about glutathione (see the 'Introduction' section) do not mention the halflive time of that food complement. Only two ones [www.glutathion. com/public/gsh.htm; www.glutathionhms.com/id151.html] inform that the commercialized glutathione has a "short half-life time", without defining this time. Our present study on the decrease of the effect of glutathione after the end of its consumption can thus bring new information on that nowadays largely used food complement.

During the two first hours after weaning, glutathione kept its effects on the ants' linear speed (Table 6, Figure 3) and activity (personal observation). Thereafter, the food complement lost its effect. Four hours after weaning, it was still active since its effect on the ants' linear speed was statistically similar to that before weaning $(\mathrm{P}=0.43)$ though less pronounced (Table 6), and the obtained values still statistically differed from the control ones $(\mathrm{P}=0.0256)$. Five and an half hours 
after weaning, the effect of glutathione approached the limit of being different from that before weaning $(\mathrm{P}=0.11)$, and the ants' linear speed no longer differed from the control one $(\mathrm{P}=0.16)$. Seven hours after weaning, the effect of glutathione became statistically different from its initial one $(\mathrm{P}=0.0176)$, and the ants appeared to walk this time nearly as usually $(\mathrm{P}=0.80)$. After that, the ants' linear speed (and activity) went on decreasing, becoming, $81 / 2$ hours after weaning, similar to the control one $(\mathrm{P}=1)$. Unexpectedly, ten hours after weaning, the ants were far less active (personal observation; Figure 3, left photo) and walked more slowly than when under normal diet: their linear speed was statistically lower than their usual one $\left(\mathrm{P}=0.02 ; \chi^{2}=16.81\right.$, $\mathrm{df}=3, \mathrm{P}<0.001)$. The ants recovered until $12^{1 / 2} 2$ hours after weaning, and became at that time no longer less active (personal observation; Figure3, right photo). They walked at their usual locomotion speed (linear speed at $\mathrm{t}=12^{1 / 2} \mathrm{~h}$ compared with control linear speed: $\mathrm{P}=1, \chi^{2}$ $=1.58, \mathrm{df}=3,0.50<\mathrm{P}<0.70)$. The decrease of the effect of glutathione since 2 hours until 10 hours after weaning was a linear function of the running time, what can be represented by:

\section{$\mathrm{Et}=\mathrm{Ei}-0.795 \mathrm{t}$}

(with $\mathrm{Et}=$ median value of the effect at time $\mathrm{t}, \mathrm{Ei}=$ initial effect, $t=$ running time, and $0.795=$ the mean of the angular coefficient of the different lines obtained in the course of the successive tests). That mean angular coefficient was rather large (i.e. $~ 0.8$ ), accounting for a rapid decrease of $E=$ the effect. In fact, since two hours after weaning, glutathione lost 0.8 of its effect during each running hour. The effect of the food complement varied from about 17.5 to $13.5 \mathrm{~mm} / \mathrm{s}$, equaling thus about $4.0 \mathrm{~mm} / \mathrm{s}$. The loss was 0.8 of $4.0 \mathrm{~mm} / \mathrm{s}$ per hour, the effect being thus lost in $4.0 / 0.8=5$ hours. This is what was observed: glutathione lost its effect from $2-2 \frac{1}{2}$ until 7-71/2 hours after weaning, so in 5 hours. Such a rapid decrease of the effect of glutathione may be perceived by consumers who may be incited to consume again the food complement in order to go on having their physical or cognitive performances enhanced. To summarize, after its consumption was stopped, the effect of glutathione stayed intact during about two hours, then rapidly decreased during five hours, and after that, if not consumed again, induced a recovering period which lasted about four hours and during which the ants were less active than usually. After all this, the ants were exactly as before having consumed glutathione. Such a rapid decrease and the occurrence of a less active period 8 to 12 hours after the last consumption of the food complement may incite humans to consume again and again it, what finally may lead to addiction. We did not know if a continuous use of that food complement could have an adverse effect on the physiology, the health, and the tiredness of the consumers, but we cautiously presumed that such a glutathione use may lead to some health problems.

\section{Conclusion}

Glutathione is a natural substance present in every cell, and nowadays available as a food complement, the consumption of which is deemed to ameliorate the health and solve several health problems, among others neurodegenerative diseases, cancer, diabetes, as well as lung, vascular, intestinal, and kidneys diseases, ${ }^{1,25-34}$ references consulted about 100-400 times).

Using ants as models, we could precise the effects of this food complement available in every drugstore. A priori, it has no adverse effect, not impacting the cognitive abilities, the social relationship, the tactile, visual and olfactory perception, and the memory, at least at the advised dose. However, even if consumed at that dose, it decreases food consumption, and increases general activity, audacity, speed of locomotion and, slightly, cognitive abilities. Also, no adaptation and no habituation occur to these effects. Moreover, glutathione leads to some dependence, and, after weaning and having then stayed intact for two hours, its effect rapidly decreases, in about 5 hours, from $2-2 \frac{1}{2}$ to $7-71 \frac{1}{2}$ hours after weaning. Moreover, a subsequent recovering period then occurs for about four hour. We suspected some doping effect for this food complement and cautiously presumed that humans consuming glutathione may perceive its enhancing effects, the lost of this effect, the occurrence of a recovering period, and may be inclined to consume it again, to use it as a doping substance, and might finally became dependent on it. In the 'results and discussion' section, we have discussed every specific points relative to our experiments. We have also compared our results to those of other researchers, what we summarize here below. No adverse effect is mentioned in easily available internet sites (see the introduction section and here above) as well as in the notice joined to this food complement. However, other internet sites relate severe adverse effects for glutathione consumption (see the 'Introduction' section). It is the reason why we undertook the present work. Our results were in agreement with those of studies showing the food complement has favourable effect, and with those of studies revealing its adverse effects. Then, after having completed the experiment on addiction and had the presumption that glutathione may be used as a doping substance, we discovered a not easily available site $\left({ }^{35}\right.$ visited about 4,000-5,000 times!) stating this fact. Our presumption was correct. Such a probable effect of glutathione must be known by concerned persons (practitioners, pharmacists, any challenge organizers), so that it could be checked if humans do not use this easily available food complement for increasing their performances, i.e. using it as a doping product.

We thus conclude that glutathione 1) must be used in case of deficit, malnutrition, and severe illness (nervous deficiencies, cardiac problems, hepatic problems, kidneys problems, cancer ...) which can be partly reduced by this food complement, 2) can be used for a short time period in case of momentary excess of work or when high performance is absolutely required, 3 ) must never be used for a long time period for a continuous artificial increase of physical and/or cognitive performances and limit of resistance, and this recommended avoidance should be checked in adequate circumstances.

\section{Acknowledgements}

We are very grateful to Dr. A. Fauteux who informed us about the possibility of obtaining glutathione, and to Dr. R. Cammaerts who helped us with the writing of the paper and the analysis of the decrease of the effect of glutathione after weaning.

\section{Conflict of interests}

We affirm having no conflict of interest concerning the use or the interdiction of use of the food complement glutathione. We are ethologist, working on ants, and receive no money for making our research. We also affirm having maintained the ants in their best living conditions.

\section{References}

1. Bray TM, Taylor CG. Enhancement of tissue glutathione for antioxidant and immune functions in malnutrition. Biochemical Pharmacol. 1994;47(12):2113-2123.

2. Wehner R, Gehring W. Biologie et physiologie animales. De Boeck Université, Paris: Thieme Verlag; 1999. p. 1-844. 
3. Sherwood L, Klandorf H, Yancey P. Physiologie animale. De Boeck superieur Editors, Belgium: 2016. p. 1-904.

4. Bousquet C. Bêtes de science. Seuil: 2003. 240 p.

5. Wolf FW, Heberlein U. Invertebrate models of drug abuse. J Neurobiol. 2003;54(1):161-178

6. Andre RG, Wirtz RA, Das YT. Insect Models for Biomedical Research In: Woodhead AD, editors. Non mammalian Animal Models for Biomedical Research. USA: CRC Press; 1989. p. 62-70.

7. Keller RA. A Phylogenetic analysis of ant morphology (Hymenoptera: Formicidae) with special reference to the Poneromorph subfamilies. Bull Am Museum Nat Hist. 2011;355:1-90.

8. Billen J, Morgan ED. Pheromone communication in social insects sources and secretions. In: Vander Meer RK et al. editors. Pheromone Communication in Social Insects: Ants, Wasps, Bees, and Termites. USA: West view Press; 1998. p.1-33.

9. Hölldobler B, Wilson EO. The ants. Harvard University Press, Berlin: Springer-Verlag; 1990. $732 \mathrm{P}$.

10. Passera L, Aron S. Les fourmis: comportement, organisation sociale et évolution. UK : Les Presses Scientifiques du CNRC ; 2005. p. 1-480.

11. Cammaerts MC. Adverse effects of a natural product allowing decreasing the amount of cholesterol in blood; a Study Using Ants as Models. MOJ Biol Med. 2017;1(3):00013.

12. Cammaerts MC, Cammaerts D. Comparative outlook over three Myrmica species' biotopes and foragers' know-how. Biologia. 2014;69(8):10511058 .

13. Cammaerts MC, Cammaerts R. Ontogenesis of ants' cognitive abilities (Hymenoptera, Formicidae). Adv Stud Biol. 2015;7(7):349-350.

14. Cammaerts MC, De Doncker P, Patris X, et al. GSM 900MHz radiations inhibits ants' association between food sites and encountered cues. Electrom Biol Med. 2012;31(2):151-165.

15. Cammaerts MC, Rachidi Z, Bellens F, et al. Food collection and responses to pheromones in an ant species exposed to electromagnetic radiation. Electrom Biol Med. 2013;33(3):282-288.

16. Cammaerts MC. Ants as biological models for studying effects of substances used by humans. JSM Anat Physiol. 2016;1(1):1003.

17. Cammaerts MC, Cammaerts R. Ethological and physiological effects of paroxetine, the nowadays most consumed antidepressant. A study on ants as models. Research Trends. 2016;12:107-126.

18. Cammaerts MC, Cammaerts D. Potential harmful effects of Carbamazepine on aquatic organisms, a study using ants as invertebrate models. Int J Biol. 2015;7 (3):75-93.

19. Cammaerts MC Physical addiction occurs when the effects of the consumed substance rapidly decreases for a time after its consumption was stopped. Frontiers in Physiology.
20. Cammaerts MC. Biological effects of curcuma, a potential safe analgesic; a study on ants as models. EC nutrition. 2017;11(3):99-116.

21. Siegel S, Castellan NJ. Non-parametric statistics for the behavioral sciences. Singapore: McGraw-Hill Book Company; 1989. 396 p.

22. Cammaerts MC, Morel F, Martino F, An easy and cheap software-based method to assess two-dimensional trajectories parameters. Belg J Zool. 2012;142:145-151.

23. Cammaerts MC, Gosset G, Rachidi Z. Some physiological and ethological effects of nicotine; studies on the ant Myrmica sabuleti as a biological model. Int J Biol. 2014;6(4):64-81.

24. Cammaerts MC, Rachidi Z, Cammaerts R. Physiological and ethological effects of alprazolam, using ants as biological models. World $J$ Pharmaceu Sci. 2016;4(6):474-489.

25. Julius M, Lang CA, Gleibeman L, et al. Glutathione and morbidity in a community-based sample of elderly. J Clin Epidemiol. 1994;47(9):10211026.

26. Jenner P. Oxidative damage in neurodegenerative disease. Lancet. 1994;344:796-798.

27. Bounous G, Batist G, Gold P. Whey proteins in cancer prevention. Cancer Lett. 1991;57(2):91-94.

28. Meister A, Anderson ME. Glutathione. Ann Rev Biochem. 1983;52:711760 .

29. Herzenberg LA, De Rosa SC, Dubs JG, et al. Glutathione deficiency is associated with impaired survival in HIV disease. Proc Natl Acad Sci USA. 1997;94(5):1967-1972.

30. Stamler JS, Slivka A. Biological chemistry of thiols in the vasculature and in vascular-related disease. Nutr Revi. 1996;54(1 Pt 1):1-30.

31. Thornalley PJ, McLellan AC, Lo TWC, et al. Negative association between erythrocyte reduced glutathione concentration and diabetic complications. Clinical Science. 1996;91(5):575-582.

32. Peter E, Morris MD, Gordon R, et al. Significance of glutathione in Lung disease and implications for therapy. The Amer J Med Sci. 1994;307(2):119-127.

33. Sido B, Hack V, Hochlehnert A, et al. Impairment of intestinal glutathione synthesis in patients with inflammatory bowel disease. Gut. 1998;42(4):485-492.

34. Costagliola C, Romano L, Scibelli G, et al. Anemia and chronic renale failure: a therapeutical approach by reduced glutathione parenteral asministration. Nephron. 1992;61(4):404-408.

35. Lands LC, Grey VL, Smountas AA. Effect of supplementation with a cysteine donor on muscular performance. J Appl Physiol. $1995 ; 87(4): 1381-1385$ 